\title{
Introduction to the Special Issues on the Supervision of Staff and Field Education of Students
}

\author{
Marion Bogo ${ }^{1} \cdot$ Karen M. Sewell ${ }^{1}$ \\ Published online: 15 October 2018 \\ ○) Springer Science+Business Media, LLC, part of Springer Nature 2018
}

\begin{abstract}
Two Special Issues of the Clinical Social Work Journal have been dedicated to building on the social work discipline's tradition and commitment to the supervision of staff and field education of students. These issues bring together contemporary theorizing, clinical supervisory and field education practice experience and wisdom, and research studies to contribute to the knowledge base for practicing supervisors and field educators. As the first of the Special Issues, this issue has been dedicated to the supervision of staff. In this Introduction, we share the salient aspects of the articles published, as they relate to contemporary social work supervision, relational considerations within the supervisory dyad, models of supervision for fields of specialization, as well as measurement and evaluation. Implications are shared, with highlights and connections for practicing supervisors made throughout.
\end{abstract}

Keyword Clinical supervision $\cdot$ Field education $\cdot$ Social work $\cdot$ Special issue

At its heart, clinical social work involves working toward the "mental, emotional, and behavioral well-being of individuals, couples, families, and groups" (National Association of Social Workers 2005, p. 7). Intentionally leveraging a complex set of practice behaviors tailored uniquely to the individual and the circumstances of client experience requires not only breadth and depth of professional knowledge and skill, but also cognitive and affective competence (Bogo 2018; Council on Social Work Education 2015). Recent shifts in political and resource conditions present an array of ever-changing challenges for both social work students entering the profession and experienced practitioners. How can students learn to be effective practitioners, and how can practicing social workers find consistent support as they develop their competence over time? Enduring professional commitments to this endeavor are the highly valued processes of field education of students and supervision of staff. The two Special Issues of the Clinical Social Work Journal build on this tradition and commitment, bringing together contemporary theorizing, clinical supervisory and field

Marion Bogo

marion.bogo@utoronto.ca

1 Factor-Inwentash Faculty of Social Work, University of Toronto, 246 Bloor Street West, M5S 1V4 Toronto, ON, Canada education practice experience and wisdom, and research studies to contribute to the knowledge base for practicing supervisors and field educators.

Initially conceptualized as one issue, the development of the Special Issues began with a call for papers which elicited substantial response from the social work community at large. With over 100 abstracts submitted, we were astounded by the interest and commitment. These abstracts came largely from faculty members in schools of social work, with some agency-based field educators and researchers joining with faculty members to produce papers. It is heartening to note this attention to the topic of supervision and field education, and it is our hope that these Special Issues of the Clinical Social Work Journal will stimulate further scholarly and practice contributions on this important topic.

As the first of two Special Issues, the current one will focus on the supervision of staff. While the term supervision is often used to refer to processes with both staff and students, we have made an important distinction (Bogo and McKnight 2005). Historically, and indeed until today, agencies employ supervisors to provide accountability for their services to clients. These supervisors oversee the work of front-line social workers for the purpose of providing the best possible client outcomes. In their roles as supervisors they provide consultation and education which in turn promotes the professional development of the staff member. 
Given the nature of client situations presented to social workers, another dimension of supervision involves offering emotional support. This three part conceptualizationadministration, education, and support-was identified by Kadushin (1976) and remains meaningful in contemporary agency settings.

The next issue of the Journal is dedicated to Field Education of students. Field education is an educational endeavor, a component of all university-based social work programs. Students pay tuition to attend courses and to receive field instruction in an agency setting. In most countries and models, agencies voluntarily provide professional social work staff who teach, support, and mentor students as they learn to apply theory to practice, to function in an agency setting, and to develop professional competence. While many of the processes used by field instructors are similar to those of staff supervision, the context and purpose are very different. Similarly, the scholarly and practice literature as well as empirical studies in social work focus on either staff supervision or field education of students. Since currently there are two separate and robust bodies of knowledge, we have separated articles on staff supervision and field education with the former appearing in this Special Issue and the later in the next Special Issue.

In this Special Issue dedicated to the supervision of staff, we have brought together important papers demonstrating different aspects of this topic, all with implications for practicing supervisors. The first three papers provide an overview of staff supervision. In an attempt to map the literature relevant to staff supervision, in the first paper in this issue Sewell provides an orientation to the literature beginning with a primer that provides definitions and clarifies the various disciplinary perspectives. This paper includes a scoping review which will help practicing supervisors who wish to keep current with the literature and apply emerging knowledge and findings from studies to their practice. The second of these overview papers is a Commentary by Migdole from Yale Behavioral Health. He discusses the context of supervision, highlighting important issues related to supervision in public sector organizations where it is crucial to have knowledge of government funding and service policies. In the third paper Choy-Brown and Stanhope report on a survey of a multi-state and multi-site NIMH trial of providers in behavioral health settings that identifies the availability and nature of supervision that staff receive.

The next group of papers provide theoretical frameworks with carefully considered applications to practice. Practicing supervisors will find a wealth of useful insights they may use in their work. The first paper in this group builds on psycho-dynamic theory, a perspective that has long contributed to knowledge of clinical supervision. Rasmussen and Mishna continue this tradition, familiar to readers of the Clinical Social Work Journal, and use a relational approach to both clinical practice and the supervisory relationship. They demonstrate the congruence between this approach and social work values such as authenticity, mutuality and collaboration.

A focus on issues of diversity and difference within the supervisory relationship are then explored. Scholars in human service professions are committed to develop and elucidate relevant dynamics, issues and, importantly, ways to use concepts in supervisory practice. Since social work in general is concerned with integrating diversity into generic practice, it is important that supervisors expand their work in this regard. Three papers contribute important insights and guidelines for supervisors. Asakura and Maurer identify key elements involved in incorporating a social justice lens in clinical supervision and use a case example to illustrate their recommendations. O'Neill and del Mar Fariña introduce their model of Critical Conversations to examine enactments of racial and social injustice in clinical supervision. The purpose is to produce change with parallel insight and action involving supervisee, supervisor, and client care. A case scenario is offered to demonstrate its application. Lee and Kealy provide a model for cross-cultural supervision based on the concepts of the supervisory alliance and practice competence. Of use to supervisors is their inclusion of specific verbatim prompts that can be employed to promote self-reflexivity in supervisees' practice.

As well as papers on generic aspects of supervision, it has become apparent that there are models of supervision developed especially for particular fields of specialization. This reflects contextual issues, that supervision is part of larger helping systems and influenced by the nature of the population, issues presented, and organizational policies and practices. Kaplan, Silverstone, Zlotnik, Herman, and Touma describe a cutting-edge project, the Supervisory Leaders in Aging (SLA) program of the National Association of Social Workers (NASW). This initiative was designed to improve social work services in gerontology by strengthening supervision of the workforce.

Supervision of staff in child welfare has been the site of much of the available supervision research to date, specifically with regard to evaluating worker outcomes. Lietz argues for the inclusion of clinical elements within supervisory relationships and functions within this sector. Highlighting the challenges connected to mandates, as well as risk and administrative agendas, she makes a strong case for the need to include an educational focus within child welfare supervision. Sharing her Strengths-Based Supervision model, she illustrates key considerations of the model and the supporting evidence, which is brought to life with her own experiences and a case example of the model in action.

Continuing to highlight the importance of the educational and supportive functions in child welfare supervision, the next paper, from Israel, contributes further empirical support 
for the impact of supervision on workers in child welfare. Weiss-Dagan, Ben-Porat, and Itzhaky share findings from their study in which they examined how role characteristics associated with child welfare work, along with the three specific supervisory functions of administration, education, and support effect workers' perceptions of supervisory effectiveness. Their results provide a unique look at how the context of this work, along with the supervisory focus, impact workers' experiences.

When it comes to empirically demonstrating the value of supervision, social work as a discipline joins the other helping professions in experiencing ongoing challenges in moving beyond the perceptions of those involved. The current state of research with respect to the supervision of staff is limited. Through sharing an innovative approach of using observation of a simulated supervision session in combination with supervisee skill ratings, Wilkins, Khan, Stabler, Newlands, and Mcdonnell meaningfully engage in this discussion. Strickler, Valenti, and Mihalo also address the issue of supervision outcome measurement, yet more importantly look to provide a tool that can support supervisory discussions and alliance building. While neither of these studies provided support for the authors' initial hypotheses, these scholars have not shied away from the difficult task of establishing ways to measure and evaluate supervision, and in sharing their efforts contribute to collective learning.

We leave the final word in this Special Issue to one of the pioneers and leading figures in the development of social work supervision, Professor Emeritus Lawrence Shulman. In an interview with Shulman, he shares his insights as he looks both back across his career as well as forward to reflect on developments over time, address contemporary issues, and anticipate future trends.

We were gratified to see the interest in the topic of clinical supervision of staff. We hope this Special Issue will stimulate supervisors and scholars to reflect on and write about current issues in supervision, develop researchable questions and carry out studies that contribute to supervisory practice.
The goal is to continue to enhance this crucial activity which contributes to social workers' professional development and ultimately to positive outcomes for clients.

\section{Compliance with Ethical Standards}

Conflict of interest The authors declare they do not have any conflict of interest.

Research Involving Human Participants or Animals This article does not contain any studies with human participants or animals performed by any of the authors.

\section{References}

Bogo, M. (2018). Social work practice: Integrating concepts, processes, and skills (2nd ed.). New York: Columbia University Press.

Bogo, M., \& McKnight, K. (2005). Clinical supervision in social work: A review of the research literature. The Clinical Supervisor, 24(1/2), 49-67.

Council on Social Work Education. (2015). Educational policy and accreditation standards (EPAS). Alexandria, VA: Council on Social Work Education.

Kadushin, A. (1976). Supervision in social work (1st ed.). New York: Columbia University Press.

National Association of Social Workers. (2005). NASW clinical social work standards. Washington, D.C.: National Association of Social Workers.

Marion Bogo is Professor at the Factor-Inwentash Faculty of Social Work, University of Toronto, Toronto, Canada. Her scholarship and research focuses on social work education for practice, particularly conceptualization and assessment of holistic competence and field education

Karen M. Sewell is a $\mathrm{PhD}$ candidate, course instructor and research coordinator at the Factor-Inwentash Faculty of Social Work, University of Toronto. Her research focuses on clinical supervision, informed by clinical experience in child/youth mental health. She is involved in social work education research on holistic competence, and simulation 